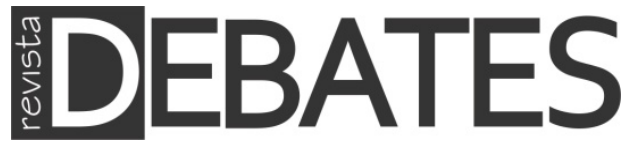

\title{
Inovações democráticas e democracias representativas
}

\author{
Democratic Innovations and representative democracies
}

\section{Mark E. Warren}

\section{Resumo}

Nossas democracias estão enfrentando desafios profundos, desde os sistemas econômicos que estáo afetando muitos cidadãos, até questôes globais de meio ambiente, segurança e migração que cruzam as fronteiras nacionais. As eleiçôes estấo cada vez mais falhando na promoção de governos com capacidades suficientes para enfrentar esses desafios, ampliando a insatisfação de amplos segmentos de cidadãos, o déficit de nossos sistemas de representação, e o eleitorado de populistas autoritários. Podemos complementar as democracias representativas eleitorais com inovaçóes que respondam a esses déficits democráticos? Embora a democracia eleitoral esteja sendo crescentemente desafiada, a "democracia" não está em crise. Na maioria dos países, os valores democráticos são fortes e estão se consolidando. Precisamos pensar sobre as inovaçôes democráticas sistematicamente, em termos dos tipos de valores que elas capturam e das deficiências de desempenho que poderão enfrentar. Ao fazermos isso, podemos refinar uma agenda para o campo das inovaçóes democráticas focada no projeto democrático, para além das instituições legadas da democracia eleitoral.

\section{Palavras-chave}

Democracia; Inovaçóes Democráticas; Democracia Representativa; Crise de Democracia.

\section{Abstract}

Our democracies are facing deep challenges, from economic systems that are failing many citizens to global environmental, security, and migration issues that flow across borders. Elections increasingly fail to return governments with capacities sufficient to meet these challenges, leaving broad segments of citizens disaffected, our systems of representation in deficit, and populist authoritarians with widening constituencies. Can we supplement electoral representative democracies with innovations that speak to these democratic deficits? While electoral democracy is increasingly challenged, "democracy" is not in crisis. In most countries, democratic values are strong and strengthening. We need to think about democratic innovations systematically, in terms of the kinds of values they capture, and the performance weaknesses they might address. When we do so, we can refine an agenda for the field of democratic innovations focused on the democratic project beyond the legacy institutions of electoral democracy.

\section{Keywords}

Democracy; Democratic Innovations; Representative Democracy; Crisis of Democracy. 


\section{Introdução ${ }^{1}$}

Estamos vivendo um período de esperança e de temor pela democracia. Os temores estão mais aparentes, relacionados com os surtos de populismo autoritário na maioria dos países da Europa, bem como nas democracias mais desenvolvidas, além de uma série de reveses no projeto da Uniáo Europeia. Em contraste com desafios anteriores, as ameaças ao projeto democrático atual estão menos relacionadas à criação de outras formas de governo, e dizem respeito às incompatibilidades entre os problemas que os povos e as sociedades enfrentam e as capacidades das democracias representativas para enfrentá-los. Onde a incompatibilidade se torna um abismo, mecanismos há muito associados ao governo democrático, particularmente as eleiçôes competitivas, tornam-se um veículo para populistas autoritários minarem outras instituiçóes, igualmente necessárias, incluindo aquelas associadas ao Estado de direito e aos direitos que definem e fortalecem a cidadania democrática (GALSTON 2018, MOUNK 2018, LEVITSKY e ZIBLATT 2018, DIAMOND 2020). Embora os padróes variem de país para país, vemos líderes eleitos com tendências autocráticas, em locais onde a democracia representativa foi estabelecida há muito tempo, utilizando-se de ferramentas centrais do projeto democrático para erodir as instituições democráticas. Assim, tememos que as democracias estejam se desgastando precisamente por meio das instituiçôes eleitorais que passaram a defini-las.

Se esses são os temores, quais são as esperanças? Em primeiro lugar, é importante destacar os ganhos associados ao projeto democrático, para que os desafios atuais não se desviem de suas realizaçóes históricas mundiais. Embora as causalidades sejam complexas, as classificaçôes acerca da qualidade da democracia tendem a ser altamente correlacionadas com quase todas as medidas de bem-estar social. Democracias fortes tendem a ser mais ricas, mais saudáveis, mais felizes, mais inovadoras, menos violentas, menos corruptas, mais pluralistas e tolerantes, melhores para as mulheres e para as minorias, e mais atentas aos setores mais pobres. Existem poucas razóes para se pensar em outros caminhos políticos para a conquista desses ganhos de bem-estar, que não a democracia, apesar dos recentes sinais de fascínio pela "epistocracia" (BRENNAN, 2017). Até o momento, as experiências de apenas dois países sugerem esse caminho como alternativa viável à democracia: Singapura, que é o

\footnotetext{
${ }^{1}$ Versão em português do capítulo: Mark E. Warren, "Democratic Innovations and Representative Democracies." In Anxieties of Democracy. Edited by Claudia Landwehr, Armin Schäfer, Thomas Saalfeld. Cambridge University Press (forthcoming). Agradecemos aos Editores a concessão de licença para a sua publicação no presente dossiê.
} 
único país que figura na maioria dos indicadores de boa sociedade para se viver, ao lado das democracias desenvolvidas, e a China, cujos líderes olham para Singapura em busca de inspiração (BELL, 2015; ORTMAN e THOMPSON, 2016). Mas, por razóes estruturais, culturais e dependentes da trajetória, é pouco provável que países democráticos desenvolvidos sigam este caminho epistocrático em resposta às fragilidades institucionais da democracia eleitoral.

Em segundo lugar, embora o projeto democrático pareça ter atingido uma "pausa" nos últimos anos, não estamos observando um retrocesso nas democracias desenvolvidas, como um projeto geral (NORRIS, 2017; NORRIS e INGLEHART 2018; TRIESMAN, 2018). Em vez disso, estamos vendo fragilidades da democracia eleitoral e das instituiçóes que a fazem funcionar, incluindo os partidos políticos. Essas fragilidades não são pequenas: o projeto democrático não pode sobreviver sem eleições, votos e as formas de representação e responsividade que ele idealmente oferece. Mas, devo argumentar, que os caminhos para uma democracia melhor, mais estável e mais progressista, envolverão a complementação do legado das nossas instituiçôes eleitorais de democracia representativa com o que veio a ser chamado de "inovaçóes democráticas" - processos geralmente associados a uma maior participação do cidadáo, melhor representação, e deliberação de maior qualidade (SMITH, 2009; ELSTUB e ESCOBAR 2019, ver também BÄCHTIGER et al, 2018).

Para se pensar as implicaçóes da "democracia", precisamos ir além de identificá-la com tipos específicos de instituiçôes, como eleiçôes competitivas e legislaturas eleitas. Embora esses tipos continuem a ser centrais, deveríamos pensar a "democracia" como uma norma de autogoverno coletivo realizável por meio de diversas práticas e instituiçóes. Para que o projeto democrático continue a se expandir e se aprofundar, devemos olhar para um futuro em que os espaços de participaçáo, representação, deliberação e decisão sejam pluralizados e desconcentrados, com as instituições de democracia representativa orientando as demandas políticas e focando em questôes estruturais de alto nível. A legitimidade democrática será, muito provavelmente, um bem distribuído que combina diferentes tipos de práticas e instituiçóes, incluindo a democracia eleitoral, mas não se limitando a ela (ROSANVALLON, 2011).

As inovaçóes democráticas que tornarão esse futuro possível já estão em curso Ao mesmo tempo em que a democracia eleitoral se enfraqueceu, temos visto milhares de experiências com novas e diferentes formas de responder e engajar indivíduos e grupos (PARTICIPEDIA, 2020), frequentemente em resposta a sociedades civis mais qualificadas para participar e também, para protestar, vetar e expressar insatisfação. 
Considerando serem recentes essas tendências emergentes, permanece o desafio de se inovar as modalidades de democracia com os tipos de capacidades e de estruturas de incentivos que as adaptem aos lugares nos quais são mais necessárias.

$\mathrm{Na}$ primeira parte deste trabalho, discuto os desafios da democracia representativa (ou democracia eleitoral), com um foco particular em algumas dinâmicas estruturais. A democracia eleitoral - particularmente os canais de representação eleitoral - mostra-se cada vez mais insuficiente para enfrentar os desafios das democracias desenvolvidas. Em segundo lugar, destaco que os valores democráticos não estão em crise, pelo menos não no contexto das democracias desenvolvidas. De fato, nesses países, os valores democráticos são fortes, estáveis e em frequente desenvolvimento. $\mathrm{O}$ que temos hoje, muito provavelmente, é um problema de desempenho: nossas instituiçóes da democracia eleitoral são necessárias, mas não suficientes para enfrentar os desafios estruturais das últimas décadas (particularmente os da globalização e da internet), nem são capazes de satisfazer cidadãos cujos valores democráticos são fortes e assertivos (FERRIN e KRIESI, 2014; KRIESI, 2020; NORRIS e INGELHART, 2018; DALTON, 2013). Em terceiro lugar, precisamos pensar sobre as inovaçóes democráticas de forma sistemática, em termos das oportunidades que estão se desenvolvendo nos sistemas políticos de hoje (WARREN, 2017). Finalmente, ao fazermos isso, podemos refinar uma agenda para o campo das inovaçôes democráticas voltada para o avanço do projeto democrático no contexto das instituiçóes da democracia eleitoral. No entanto, permanecem questóes em aberto: será possível inovar suficientemente rápido? E estarão as elites políticas suficientemente abertas a essas inovaçôes, permitindo sua implementação? Do contrário, se mantém a possibilidade de que a atual fraqueza das instituiçóes da democracia eleitoral se amplie de forma a ameaçar o projeto democrático.

\section{Uma crise de democracia?}

Nas democracias desenvolvidas, os sinais de que nem tudo está bem já existem há algum tempo, uma vez que as taxas de votação nas eleiçôes permanecem estagnadas (NORRIS, 2011) e a desconfiança no governo, especialmente por parte do público menos informado, permanece insistentemente alta (EDELMAN, 2019). Líderes e partidos populistas com tendências autoritárias e anti-imigrantes têm conseguido mobilizar o descontentamento e ampliar o poder nos EUA, no Reino Unido, na Alemanha, na França, na Itália e em muitos dos países da Europa Oriental, enquanto os partidos populistas de direita vêm ganhando assentos nas legislaturas de 
praticamente todos os países da Europa Ocidental (NORRIS e INGELHART, 2018), nos Estados de sistemas federados, e no Parlamento Europeu. Os partidos e as coalizóes de centro parecem estar em colapso, desde a tomada do Partido Republicano nos EUA por Trump, até o enfraquecimento, e quase colapso, das coalizóes de centro de longa data nos países da Europa Ocidental. O crescente colapso do centro reflete um aumento da polarização eleitoral da população, como sugerem os sucessos de ambos os partidos de direita e de esquerda nas recentes eleiçóes para o Parlamento Europeu. Certamente, o quadro não é uniforme: a população dinamarquesa, por exemplo, permanece relativamente satisfeita com o seu sistema, enquanto americanos, italianos e britânicos estáo bem menos satisfeitos.

Apesar desses descontentamentos, devemos manter alguma cautela, tanto com relação à ideia de "crise", quanto com a de "democracia". O registro acadêmico de anúncio de crise da democracia é pobre (ver por exemplo, CROZIER et al., 1975; cf. WARREN, 2014), provavelmente por que, mesmo com os sistemas políticos democráticos apresentando baixo desempenho, eles evoluíram de modo a absorver choques e promover ajustes. A governança democrática é multi-institucional e é distribuída entre as áreas de políticas, com variados tipos de mecanismos de representação e de responsividade, e que são oriundos não apenas dos sistemas eleitorais, como também das redes de governança, das estruturas administrativas diferenciadas, e das organizaçôes não governamentais. É provável que os desafios atuais da democracia estejam relacionados, principalmente, com problemas da democracia eleitoral e de suas formas de representação - pelo menos nas democracias desenvolvidas focadas aqui. Nesse contexto, a arquitetura institucional da democracia eleitoral está interagindo mal com as mudanças estruturais, e produzindo descontentamentos que são cada vez mais evidentes.

As fontes desses descontentamentos são bem conhecidas. A mais importante entre essas dinâmicas estruturais é a globalização das economias, especialmente nas democracias desenvolvidas. A globalização produziu economias mais ricas, mas a maioria dos ganhos vai para aqueles que já são os mais ricos, mais altamente qualificados e já inseridos nas economias do conhecimento, particularmente, mas não apenas, nos Estados Unidos (GILENS, 2012, HUBER, et. Al, 2020). Aqueles sem recursos, habilidades ou educação se veem competindo por baixos salários em economias do exterior, sendo substituídos pela automação na indústria e, em muitos serviços, competindo com os imigrantes por empregos de baixa qualificação. Essas tendências são atenuadas em países com estados de bem-estar fortemente redistributivos, como a Dinamarca. $\mathrm{O}$ crescimento da internet e das redes sociais 
tornou mais fácil para os empreendedores políticos, tanto os legítimos quanto os mal intencionados, administrarem os interesses econômicos longe dos olhares dos antigos guardiōes da informação e da organização: a mídia tradicional, as organizaçôes como sindicatos e congregaçóes, e os partidos políticos.

Essas tendências desafiam o legado das instituiçóes da democracia representativa de várias maneiras. Em primeiro lugar, as forças da globalização fluem através das fronteiras, de tal forma que os Estados-nação devem escolher entre ficar para trás economicamente ou permitir que o controle da economia seja transferido para instituições globais e transnacionais, como a Organização Mundial do Comércio, a Uniáo Europeia, e o Acordo de Livre Comércio da América do Norte. Os arranjos do estado de bem-estar pós Segunda Guerra Mundial - o capitalismo de mercado relativamente livre combinado com a gestão estatal das condições e externalidades do mercado, proteçôes de bem-estar, e salários crescentes - vêm se desintegrando há várias décadas, com as recessóes de 2008 expondo suas crescentes fragilidades

Do ponto de vista da democracia, parece que, como os Estados-naçáo têm menos controle sobre as forças estruturais das economias globalizadas, aqueles eleitos para representar a população também são menos poderosos, fragilizando a soberania popular organizada no nível do Estado-nação. As forças pró-Brexit no Reino Unido apontam justamente para esse diagnóstico, assim como a promessa de que a soberania nacional do Reino Unido será recuperada da União Europeia, restabelecendo a soberania popular britânica. É importante notar que a linguagem utilizada pela reaçáo é a da "democracia" - especificamente aquela referente ao controle do povo sobre o estado-nação. Assim, precisamos observar que a ideologia nacionalista tem se mesclado, frequentemente, com a linguagem da soberania popular, exercida no nível do estadonação e institucionalizada por meio da democracia eleitoral. A globalização, neste contexto, significa uma perda de controle democrático para estruturas e instituiçóes distantes, a maioria das quais não opera democraticamente. Esse conjunto de condiçóes e o seu enquadramento como "democracia" constitui-se como um dos principais desafios para os democratas em um mundo globalmente interconectado. Precisamos de inovaçóes democráticas que possam ultrapassar as fronteiras e capacitar as pessoas para além das organizaçôes do estado-nação (DRYZEK, 2006; 2013). A UE propóe um modelo - mas esse modelo precisa complementar suas estruturas burocráticas com processos democráticos que sejam mais integradores do que o Parlamento Europeu, para que não sejam assaltadas por populismos nacionalistas como aqueles que alimentaram o Brexit. 
Em segundo lugar, a desigualdade, na maioria das democracias desenvolvidas, está regionalizada: áreas urbanas dinâmicas (por exemplo, São Francisco, Londres e Frankfurt) têm um bom desempenho, enquanto aqueles locais das indústrias do cinturão da ferrugem (áreas industriais náo modernizadas, ou áreas mais rurais), e que são incapazes de atrair novos negócios (por exemplo, partes de Ohio, West Virginia, Yorkshire e a antiga Alemanha Oriental), tenderam à estagnação. Enquanto as áreas urbanas dinâmicas se tornam lugares vibrantes, criativos, com público plural, atraentes para os imigrantes, e progressistas em suas culturas, as áreas estagnadas perdem seus ambiciosos jovens e deixam de atrair imigrantes. Nas últimas décadas, essas áreas tornaram-se mais velhas, mais brancas, menos educadas e nostálgicas de tempos passados, considerados melhores. As consequências eleitorais são gritantes: como as democracias representativas são (principalmente) organizadas por jurisdição territorial, as divisóes geográficas do eleitorado produzem polarização política - e com isso, mais revolta e mais impasse político. As áreas economicamente estagnadas tornaram-se campos férteis para os empreendedores políticos, e a competição eleitoral fornece os incentivos para mobilizar ressentimentos. Embora essas mudanças estruturais sejam comuns às democracias desenvolvidas, seus efeitos são ampliados em países como o Reino Unido, com sistemas eleitorais de voto pluralitário puro, e, nos Estados Unidos, ampliados ainda mais pela prática do gerrymandering ${ }^{2}$ da Câmara Baixa Distrital, tanto no nível estadual quanto no federal.

Em terceiro lugar, os cidadãos das democracias desenvolvidas estão se tornando, de geração em geração, mais pós-materiais, mais urbanos, mais pluralizados e geralmente mais tolerantes e progressistas ao longo dos últimos quarenta anos, aproximadamente. Essas tendências, quando combinadas com questôes de ordem demográfica, ajudam a gerar uma reação de backlash cultural entre os cidadãos mais velhos, mais brancos e menos educados (NORRIS e INGLEHART, 2018). Em muitos lugares, essa reação é alimentada pela imigração, que parece ameaçar as culturas existentes e as identidades construídas em torno delas. Em alguns casos, a imigração é o resultado de regimes de segurança falidos, como no Oriente Médio; em outros casos, a imigração da América Central para os Estados Unidos e a do Norte da África para a Europa são alimentadas pelo contraste entre as ricas áreas urbanas e os países relativamente empobrecidos. Combinados com espantosos incidentes de terrorismo,

\footnotetext{
2 Prática em que alguma autoridade muda as fronteiras de um distrito eleitoral a fim de aumentar o número de eleitores, com base nas alteraçóes demográficas.
} 
como os ataques de 11 de setembro, esses fenômenos se tornam incentivos para os populistas autoritários formularem argumentos gerais contra a imigração.

Em quarto lugar, essas tendências estão interagindo com o rápido desenvolvimento das redes sociais e do Big Data, o que torna relativamente fácil, tanto para empreendedores políticos domésticos e investidores estrangeiros mal intencionados, organizarem e espalharem rumores e desinformação, atingindo eleitores específicos com apelos psicologicamente projetados, estratégias utilizadas, por exemplo, pela Cambridge Analytica na eleição presidencial dos EUA de 2016, e no referendo do Brexit. Os incentivos estratégicos dos sistemas eleitorais competitivos tendem a apoiar e recompensar esses tipos de táticas, especialmente voltadas para os eleitores com pouca informação.

Finalmente, e de importância fundamental, é a forte manutenção de apoio aos valores democráticos nas democracias desenvolvidas. Enquanto as gerações mais velhas da população tendem a ser mais autoritárias, as mais jovens sustentam valores relacionados ao autogoverno ativo (DALTON, 2013; NORRIS, 2011; 2017; NORRIS e INGLEHART, 2018). Os valores autoritários são mais pronunciados nas democracias mais recentes (por exemplo, Hungria e Polônia), embora apareçam nas democracias desenvolvidas, principalmente entre os setores demográficos mais velhos e brancos. Esses dados são consistentes, por exemplo, com as características demográficas da base eleitoral de Donald Trump. Mesmo assim, os dados do projeto V-Dem sugerem que, mesmo globalmente, o apoio aos valores democráticos tem crescido de forma consistente e dramática no período pós-segunda guerra mundial (ALEXANDER e WELZEL, 2017, DALTON, 2013). O descontentamento com o desempenho das democracias desenvolvidas, e mesmo a desconfiança generalizada nas elites políticas, não significa que haja amplo apoio ao autoritarismo, mas pode significar a ampliaçáo de um fosso cada vez maior entre os ideais democráticos de um número crescente de cidadáos e o desempenho da democracia eleitoral. Uma implicação fundamental para as inovaçôes democráticas é a de que elas podem e devem contribuir para o fortalecimento dos valores democráticos.

Em suma, a globalização econômica, a distribuição territorial, a imigração, as redes sociais, estão agora interagindo com os incentivos estratégicos gerados por eleiçóes competitivas e pela organização da democracia eleitoral em distritos territoriais e jurisdiçóes, de modo a minar as capacidades da democracia representativa de gerar um bom governo. Se há uma "crise de democracia" na atualidade, ela é específica da representação eleitoral e das instituiçóes a ela associadas, justamente por que seus 
principais mecanismos não estão interagindo bem com as tendências das últimas décadas. Não podemos prescindir dessas características do governo democrático, mas deveríamos estar pensando em como preservar seus melhores resultados accountability, representação por localidade, e estados-nação com capacidade de atuar no âmbito das suas fronteiras territoriais - enquanto atenuamos os seus efeitos danosos. É importante ressaltar que os tipos de reformas e inovaçóes que podem resolver os deficits políticos da democracia representativa precisam se alinhar aos valores democráticos que permanecem fortes, especialmente aqueles da cidadania ativa.

Dito isso, as inovaçóes democráticas precisam estar adequadas aos lugares em que estão sendo propostas. Inovações inadequadas podem gerar ou aprofundar crises (LANG e WARREN, 2012), como fica evidente quando políticos eleitos, ao se depararem com algum tipo de problema, buscam processos extra eleitorais para aumentar sua legitimidade. Esses políticos tendem a buscar os dois tipos de suplementos políticos que melhor conhecem: referendos e audiências públicas. Embora esses processos tenham seu lugar em qualquer ecologia das instituições democráticas, às vezes podem gerar crises mais significativas do que a insatisfação que buscam resolver. As iniciativas plebiscitárias e os referendos podem ser especialmente problemáticos, visto que muitas vezes refletem agendas impulsionadas por interesses específicos que visam evitar processos legislativos, agregar preferências dos eleitores que, muitas vezes, são mal informadas, ou não conseguem mobilizar comparecimento suficiente para representar os cidadãos que as agendas afetam.

A Proposta 13 da Califórnia, conhecida como proposta de "revolta tributária", foi levada às urnas em 1978 com o objetivo de limitar os impostos sobre a propriedade, devido ao sistema eleitoral que falhou em responder aos reais prejuízos fiscais (CITRIN, 2009). Essa resultou em "restriçôes fiscais ao legislativo [que] desencadeou uma corrida louca por dinheiro, a qual produziu um sistema orçamentário incoerente e disfuncional que torna mais difícil reagir com flexibilidade em tempos de estresse fiscal".

Desde entấo, as iniciativas eleitorais da Califórnia produziram um "governo plebiscitário" que aumentou os poderes do dinheiro e dos "principais jogadores" (CITRIN, 2009, p. 7-8). O Brexit, uma proposta para retirar o Reino Unido da UE, já está prejudicando a economia do Reino Unido, provavelmente ocasionando danos ainda mais profundos quando a retirada for concluída. Neste caso, um referendo projetado para resolver uma divisáo dentro do Partido Conservador tornou-se a crise mais significativa, para a Grá-Bretanha, desde a Segunda Guerra Mundial, e, certamente, a ferida auto infligida mais desnecessária na história britânica moderna. Ao 
realizar um referendo para resolver a questão interna do partido, o governo eleito do Reino Unido mobilizou uma quantidade decisiva de desconhecimento dos cidadáos sobre uma questão altamente complexa, mergulhando o país em uma crise. As audiências públicas e outros processos semelhantes são frequentemente populares entre os políticos eleitos, pois criam performances (de um líder que escuta e responde) amigáveis à mídia. Esses processos raramente criam os tipos de crises secundárias que podem resultar de referendos e medidas eleitorais, mas muitas vezes servem mais como uma via de influência para aqueles que já estão bem organizados.

A lição é a de que suplementos democráticos precisam ser desenhados para atingir déficits democráticos específicos, focando na inclusão daqueles que tendem a ser excluídos da política eleitoral; construindo pontes representativas para os decisores; impulsionando conhecimento e competência dos cidadáos; e ampliando fronteiras territoriais.

\section{Inovações democráticas como democracia suplementar?}

Se este diagnóstico estiver correto, precisamos apostar na democracia para atingir os déficits da democracia eleitoral, e fazê-lo de acordo com os valores democráticos dos cidadáos, especialmente daqueles grupos mais jovens, cujos valores moldaráo o futuro. Precisamos inovar de forma a restaurar vínculos representativos eficazes, organizar e desenvolver as capacidades dos cidadáos, e levar adiante o projeto da boa governança, de forma a restaurar a confiança dos cidadãos. Náo estamos partindo do zero: esses processos já estão ocorrendo na maioria das democracias desenvolvidas. Apesar das ameaças atuais, podemos estar no início de uma transformação silenciosa da democracia - possivelmente tão revolucionária quanto o desenvolvimento da democracia representativa e partidária que evoluiu do direito ao voto universal (WARREN, 2003).

Estamos vendo centenas de milhares de novos canais de envolvimento dos cidadáos no governo, na maioria dos países do mundo, operando, frequentemente por fora das políticas mais visíveis da representação eleitoral, e especialmente impulsionados por problemas de governança em sociedades complexas. Muitas vezes de forma ad hoc, fragmentada e segmentada por setor de política, jurisdição e nível de governo, essas inovaçóes, quando vistas como um todo, sugerem que uma transformação na natureza e na estrutura da governança democrática pode estar em andamento (ver Participedia.net, ELSTUB e ESCOBAR, 2019; NEWTON e GEISSEL, 2012). Em muitos casos, novos processos combinam-se com outros antigos, como no exemplo da 
Revisão da Iniciativa de Cidadãos de Oregon (Oregon's Citizens' Initiative Review), que criou um pequeno minipublico deliberativo à frente de iniciativas eleitorais importantes para fazer com que os cidadáos aprendam e debatam antes de votarem (GASTIL e KNOBLOCH, 2020). Não são apenas os governos (principalmente nos níveis locais) que estão inovando, mas também um número crescente de ONGs e de consultorias especializadas em inovações democráticas (LEE, 2015). A plataforma Participedia lista mais de 600 organizaçóes com interesses em inovaçôes democráticas (PARTICIPEDIA, 2020). Paralelamente a esses processos, o campo de estudo das inovaçôes democráticas está crescendo (HEINELT, 2018; BÄCHTIGER et al,. 2018; ELSTUB e ESCOBAR, 2019). A OCDE publicou recentemente um relatório sobre as "novas instituiçôes democráticas" (OCDE, 2020). O Consórcio Europeu para a Pesquisa Política (European Consortium for Political Research) agora tem uma seção contínua dedicada às inovações democráticas. A Participedia documentou mais de cem novos processos distintos, como júris de cidadáos, assembleias de cidadãos, votação deliberativa, orçamento participativo, células de planejamento, e novas plataformas online para deliberação (PARTICIPEDIA, 2020). O estudo empírico voltado para as inovaçôes, como os minipúblicos deliberativos, está cada vez mais sofisticado e produzindo importantes insights sobre as capacidades de aprendizagem e de bom julgamento dos cidadáos, e estamos começando a desenvolver tipologias e classificaçóes (SMITH, 2009, FUNG, 2003a, 2006; ELSTUB e ESCOBAR, 2019).

Para avançar, precisamos combinar essa inventividade atual com as estruturas de oportunidade que se desenvolvem dentro e além das instituiçóes da democracia representativa. O campo das inovaçóes democráticas está apenas começando a desenvolver análises em nível de sistema, e que nos permitirão entendê-las no âmbito dos contextos institucionais legados tendo em vista atingir tipos específicos de déficits em tipos de sistemas específicos (MANSBRIDGE e PARKINSON, 2012, BÄCHTIGER e PARKINSON, 2019, WARREN, 2002, 2017; DEAN et al., 2019). $\mathrm{Na}$ falta de análises mais sofisticadas dessa abordagem da teoria dos sistemas, podemos pensar nas oportunidades das inovaçóes em três níveis: (a) aquelas que ocorrem por "dentro" das democracias representativas; (b) aquelas "abaixo" da democracia eleitoral, em áreas descentralizadas e desconcentradas de governança; e (c) aquelas "acima” da democracia eleitoral, entre e além dos Estados-nação.

\section{Oportunidades dentro da democracia representativa}

$\mathrm{O}$ voto e as instituiçóes eleitorais continuarão essenciais para as democracias, pois continuam sendo os principais organizadores das decisóes baseadas no estado e nas 
açôes coletivas, não apenas por garantir proteção aos cidadãos, mas também por desempenharem um papel chave de representação em larga escala, seja nas instituiçóes nacionais ou transnacionais, mesmo naquelas instituiçóes que precisam ser reformadas, ampliadas ou inventadas para lidar com as estruturas globalizadas. Para que essas funçóes representativas sejam democraticamente robustas, a democracia dentro dos Estados deve se tornar melhor e mais forte.

Existem reformas dos próprios sistemas eleitorais que ajudariam a preencher as lacunas de representação, como a mudança para a representação proporcional em países como o Reino Unido, EUA e Canadá que ainda usam sistemas plurais de único membro (Single Member Plurality Systems), livrando-se, no caso dos EUA, do gerrymandering, e lutando contra a supressão de eleitores.

Mais ambiciosamente, no entanto, os eleitores deveriam receber maior apoio em suas decisões infundindo, nas eleiçóes, processos deliberativos, particularmente de tipos que tornam mais difícil para os estrategistas eleitorais enquadrar e direcionar mensagens. Isso pode incluir sugestóes de longa data, como o Dia da Deliberação (ACKERMAN e FISHKIN, 2004), e novas maneiras de conectar deliberadamente representantes e constituintes (NEBLO, et. Al., 2010). Da parte dos políticos eleitos, precisamos encontrar novas formas de educá-los a respeito de outras formas de representação cidadã, para que possam aprender a confiar na população (WARREN, 2008). A Convenção Irlandesa sobre a Constituição de 2012, uma assembleia de cidadãos, reuniu políticos eleitos com cidadãos escolhidos por amostragem aleatória estratificada. Os políticos ficaram satisfatoriamente impressionados com a qualidade deliberativa dos processos que apoiaram as assembleias de cidadãos sobre o aborto e a igualdade no casamento, ambas questóes constitucionais que produziram referendos (FARRELL e SUITER, 2019).

No que diz respeito às legislaturas, existem várias propostas bem pensadas para a criação de uma segunda ou terceira câmara legislativa, selecionada aleatoriamente, e que sem dúvida teria uma legitimidade democrática mais ampla do que as câmaras eleitas, devido não apenas às qualidades representativas, mas também à alta probabilidade de serem corpos mais deliberativos do que os corpos eleitos, e nos quais os seus membros têm incentivos estratégicos que tendem a minar as suas funçóes deliberativas (DRYZEK e NIEMEYER, 2008; GASTIL e WRIGHT, 2019; LIEB, 2010). No entanto, nas democracias desenvolvidas, as mudanças nas estruturas constitucionais geralmente são extremamente difíceis de serem alcançadas, uma vez que 
mudanças institucionais profundas são usualmente impulsionadas por uma crise mais ampla, e não por desempenhos institucionais menos urgentes.

Poderiam os partidos políticos se beneficiar das inovações democráticas, especialmente de modo que lhes permitissem exercer as funções de intermediação, compromisso e construção de coalizóes, e que são apontadas, pela maioria dos cientistas políticos, como essenciais para o funcionamento das democracias representativas, porém de maneira mais inclusiva e deliberativa? Com o colapso das coalizóes centristas na maioria das democracias europeias, nos parece que os incentivos estratégicos estariam presentes. Nos Estados Unidos, é desanimador, para aqueles que veem os partidos políticos como instituiçóes essenciais da democracia representativa, que Donald Trump, um político externo e com pouco apreço por instituiçôes, tenha assumido de forma tão completa a máquina e a cultura do Partido Republicano. Sistemas de representação proporcional, com os sistemas multipartidários que produzem, são mais suscetíveis à classificação ideológica do que os sistemas de pluralidade de um único membro, com mediação e construção de coalizões geralmente ocorrendo entre as elites partidárias, muitas vezes a portas fechadas. Dados os incentivos estratégicos, é difícil ver aberturas para inovaçóes democráticas. Também náo fica claro o quanto as elites dos partidos estariam abertas a aceitar a expansão de suas categorias de base. Desde o final dos anos 1960, os partidos, na maioria dos países da OCDE, têm buscado se tornar menos controlados pelas elites partidárias e mais democráticos internamente (SCARROW, 2005). Essas reformas são, no entanto, prejudicadas pelo fato de os partidos políticos serem organizaçôes voltadas às eleiçôes competitivas, as quais sempre favorecerão estrategistas internos, e porque as eleiçóes são competitivas, os partidos buscarão se diferenciar e, entâo, representarão alguma fração do eleitorado (TEORELL, 1999). Dito isto, os partidos que buscam se tornar grandes conglomerados e encontrar formas de deliberação e compromisso para ampliar e abrir novos espaços, podem se beneficiar de uma grande variedade de técnicas no escopo das inovaçôes democráticas (TEORELL, 1999).

Além de eleger os corpos representativos, outros lugares em que a votação ocorre são os referendos e as iniciativas populares - práticas altamente institucionalizadas na Suíça e em muitos estados dos EUA. Existem vários problemas democráticos com esses mecanismos eleitorais, incluindo agendas manipuladas e falta de conhecimento do cidadão. Mas, mesmo assim, é provável que sejam utilizados cada vez mais, já que políticos e cidadãos populistas apreciam esses processos em função de sua aparente "responsividade", fazendo parecer ignorar as "elites corruptas" e os "interesses específicos" (daí o termo "democracia direta"). Precisamos pensar em como 
aprimorar esse tipo de votação, para que não haja mais crises do tipo Brexit (MCKAY, 2019). Uma das melhores inovaçôes recentes é a já mencionada Oregon Citizens' Initiative Review, que associa um júri de cidadãos (deliberativo e aleatoriamente selecionado) a iniciativas eleitorais importantes ou polêmicas, fornecendo aos eleitores uma orientação confiável (WARREN e GASTIL, 2015; GASTIL e KNOBLOCH, 2019). Ainda, os referendos podem ser realizados em duas fases, permitindo que os cidadáos reflitam sobre o assunto antes de uma segunda votaçáo (BARBER, 1983). $\mathrm{Ou}$, mais radicalmente, os referendos podem ser integrados ao processo legislativo normal, como acontece com os "referendos facultativos" da Suíça - uma possibilidade que ampliaria ainda mais a aprendizagem e a deliberaçáo do cidadão, sugerindo (novamente) combinar minipúblicos deliberativos com referendos (MCKAY, 2019, EL-WAKIL, 2017).

As aberturas para inovações democráticas são mais promissoras nas instâncias burocráticas dos estados - processos que denominei em outro lugar de "democratização orientada pela governança” (WARREN, 2009). Em muitas áreas de políticas públicas - transporte, saúde, educaçáo, desenvolvimento regional, planejamento urbano e assim por diante - a legitimidade das eleiçôes não necessariamente alimenta os mandatos das agências e ministérios. À medida que os negócios do governo se tornam cada vez mais complexos em sociedades e economias igualmente complexas, os legislativos tendem a apresentar propostas e direções e, em seguida, transferir grande parte da política para a formulação de regras administrativas. Essas tendências interagem com outras que datam da era pós-Segunda Guerra Mundial, quando as agências governamentais começaram a crescer rapidamente em suas missóes e alcances: a legislação sancionada geralmente direciona as agências e ministérios a se envolverem com os públicos afetados ao passo que as regras necessárias aos processos administrativos são postas em prática pela legislação. Enquanto essas diretivas são seguidamente executadas de formas que satisfazem minimamente os requisitos legislativos, em muitos lugares e áreas as agências têm sido mais imaginativas, criando modos inovadores de envolvimento, incluindo a relativamente bem desenvolvida "governança em rede" (network governance) da Dinamarca (SØRENSEN, 2002), e até mesmo os minipúblicos deliberativos sobre questóes difíceis, como a regulamentação da nanotecnologia nos Estados Unidos (GOODIN e DRYZEK, 2006). Nos EUA, as agências que enfrentam questóes complexas frequentemente contratam as Academias Nacionais de Ciências para obter aconselhamento. As Academias, por sua vez, consultam não apenas especialistas, mas também "partes interessadas", incluindo os públicos afetados. 
É provável que essas tendências se acelerem, proporcionando novas oportunidades para atualizar as suas dimensões democráticas. $\mathrm{Na}$ medida em que as inovaçóes democráticas, baseadas na governança, gerem legitimidade democrática em questóes específicas, elas podem, por assim dizer, aliviar os deficits democráticos experimentados pelas instituiçóes centrais da democracia eleitoral, e que geram legitimidade para plataformas mais amplas e interligadas, mas em muitos casos não para questôes específicas, com constituintes específicos (ROSANVALLON, 2011). Além disso, no âmbito da "governança", a legitimidade é menos cativa dos ciclos eleitorais e está mais intimamente relacionada ao incrementalismo da política de longo prazo. Estruturalmente, as burocracias podem descobrir que seus mandatos de governança encontram oposição organizada, ou tentativas persistentes de captura por interesses políticos específicos. Dispositivos como os minipúblicos deliberativos podem fornecer resistência democraticamente legítima ao gerarem orientação e apoio altamente representativo, informado e deliberativo, especialmente no âmbito das políticas contenciosas, ou quando os eventos fazem com que as forças políticas se alterem para dar espaço a determinadas políticas (por exemplo, BEAUVAIS e WARREN, 2019).

\section{Oportunidades "abaixo" da democracia representativa}

Desenvolvimentos estruturais que têm pressionado decisóes "abaixo" das instituiçôes da democracia representativa fornecem oportunidades mais diretas de inovação democrática (LEIGHNIGER, 2006). Desde o início dos anos 1980, muitas responsabilidades foram descentralizadas para níveis inferiores de governo por meio de novos arranjos federais (por exemplo, governos regionais autônomos da Espanha e Itália), da desconcentração de poder (mudança de decisôes para níveis inferiores de governo ou agências mais próximas da prestação de serviços) e privatização junto a empreiteiros ou entidades público-privadas. Existem riscos claros para a democracia quando entidades públicas transferem responsabilidades para entidades com mandatos e responsabilidades pouco claros. Dito isso, esses processos podem, e muitas vezes oferecem, novas oportunidades para inovaçóes democráticas.

Os governos municipais e regionais estão cada vez mais propensos a se envolver com os cidadáos em questóes locais, como planejamento de transporte, eliminação de resíduos, habitação social, educação e escolas, saúde pública, e planejamento urbano em geral (LEIGHNIGER, 2006). Os processos de engajamento podem, em parte, ser impulsionados pela ação de ativistas e açóes de advocacy que podem efetivamente travar o planejamento, mas também serem motivados pelo profissionalismo das pessoas 
envolvidas na prestação de serviços, ou serem impulsionados por compromissos com a justiça distributiva, quando têm força política (ver. LANDWEHR e FAAS, 2016). O orçamento participativo é um desses casos. Uma inovação do governo do Partido dos Trabalhadores (PT) em Porto Alegre, Brasil, que certamente ajudou a mobilizar eleitores mais pobres para o partido, mas que foi justificada como uma forma de atender às deficiências de serviços em bairros pobres (SMITH 2009; WAMPLER 2010). O orçamento participativo, agora utilizado, de variadas formas, em milhares de municípios, conecta as autoridades eleitas diretamente aos cidadáos, permitindo que eles definam o uso de porçôes dos orçamentos anuais (SINTOMER et. Al., 2012). Embora esse processo tenha se limitado a níveis locais de governo, a ampla tendência em direção à tomada de decisóes descentralizadas tem se expandido.

\section{Oportunidades "acima" da democracia representativa}

As oportunidades para inovaçóes democráticas situadas "acima" da democracia eleitoral são mais difíceis de conceituar devido ao seu escopo e distância da maioria dos cidadãos, mas elas são de importância crucial nos debates sobre os deficits democráticos. Regimes transnacionais, multinacionais e internacionais tendem a surgir para tratar de problemas de alcance global ou regional. A governança que ultrapassa os limites do Estado-nação requer legitimidade democrática, tanto quanto qualquer outro tipo ou nível de governo, sob pena do afastamento, por governos populistas, no enfrentamento aos desafios globais, como a mudança climática, a questão dos empregos e da migração, ao mesmo tempo que a perda das oportunidades globais, como os benefícios econômicos de regimes de comércio integrados.

Onde devemos procurar as oportunidades para inovações democráticas localizadas "acima" das democracias eleitorais? Primeiro, devemos prestar muita atenção ao surgimento de regimes de processos temáticos de governança, e que continuam a se desenvolver e proliferar, impulsionados por demandas altamente complexas e / ou jurisdiçóes cruzadas (por exemplo, distritos de transporte, regimes de segurança e de organizaçóes comerciais, e organizaçóes internacionais definidas por temas/questóes). Frequentemente, os regimes internacionais, multinacionais e transnacionais precisam criar a sua própria legitimidade. Por não corresponderem às regras da democracia eleitoral baseadas em jurisdição, esses regimes de governança devem criar novas bases de legitimidade, representando lugares-chave em que as inovaçóes democráticas sejam possíveis e necessárias (por exemplo, FUNG, 2003b; ISERNIA e FISHKIN, 2014). $\mathrm{Na}$ verdade, na medida em que os regimes de 
governança, especialmente os internacionais, não operam democraticamente, eles fornecem combustível ao cerceamento por parte do nacionalismo populista. Dito isso, temos visto mais inovaçáo democrática em regimes de nível mais baixo - digamos, no planejamento de transporte regional - do que em regimes transnacionais e internacionais.

Uma segunda área de oportunidades tem surgido no interior das organizaçóes dos estados membros. Formalmente, os estados devem representar a sua populaçáo junto às organizaçóes internacionais. Mas algumas organizaçóes, principalmente a ONU, o Banco Mundial e a UE, também estabelecem relaçóes com os seus constituintes, especialmente em torno de questóes intimamente relacionadas ao desenvolvimento humano e aos direitos humanos (por exemplo, pobreza, saúde, a condição da mulher, padróes de trabalho, questôes ambientais e de refugiados). Embora essa evolução da representação direta venha sendo bem reconhecida no campo, mais recentemente as ONGIs têm sido criticadas por seu paternalismo, o que tem motivado a criação de novas maneiras de envolver os seus públicos (MORAVCSIK, 2010). Essas são trajetórias que podem ser democratizadas, e que se beneficiariam das inovaçôes democráticas (KEOHANE et. Al., 2010; FUNG, 2006, DRYZEK, 2006).

Terceiro, é amplamente reconhecido que, apesar dos nacionalismos ressurgentes, a sociedade civil global continua a crescer e a se desenvolver, muitas vezes diretamente em resposta aos desafios globais (por exemplo, KEANE, 2003; KALDOR, 2003). As organizaçóes da sociedade civil voltadas a defesa de causas criam e organizam constituintes (baseados em temas e/ou questôes) informais que cruzam diferentes jurisdiçôes nacionais. Embora a maioria dessas organizaçóes não seja internamente democrática, elas desenvolvem estruturas e organizaçóes que podem ser democratizadas (GRANT e KEOHANE, 2005; MONTANARO, 2017).

\section{Onde o campo das inovações democráticas precisa se desenvolver?}

Como o campo das inovaçóes democráticas pode se desenvolver em direção a promoção dessas oportunidades de dentro, abaixo e acima da democracia representativa? $\mathrm{O}$ campo, tanto acadêmico quanto prático, ainda está em sua infância. A maioria das inovaçóes foi criada e praticada nas últimas três décadas. O campo acadêmico das inovaçôes democráticas está se organizando, e apenas mais recentemente tem se constituído como uma área distinta de estudo (ELSTUB e ESCOBAR, 2019). O campo hoje é composto principalmente por estudos de caso, ou conjuntos de casos focados em um único modelo, como o Orçamento Participativo ou a Pesquisa 
Deliberativa (JACQUET e VAN DER DOES, 2020). Há também um número crescente de tipologias que buscam categorizar e classificar os tipos de inovação (GASTIL, 2008; SMITH, 2009; PARTICIPEDIA, 2020; O PROJETO LATINNO, 2019; ELSTUB e ESCOBAR 2019). Também cresce a demanda, impulsionada pelos ativistas, de como desenhar inovaçóes democráticas para resolver problemas em contextos específicos. Assim, temos muito trabalho a fazer para descobrir quais tipos de inovaçôes democráticas podem compensar os deficits das democracias representativas, e fazê-lo de maneira que correspondam aos nossos desafios atuais. Existem pelo menos sete áreas que precisamos enfrentar.

Em primeiro lugar, precisamos recuperar e desenvolver abordagens de sistema, de base mais programática tendo em vista enfrentar os déficits democráticos e criar inovaçôes (WARREN, 2017; MANSBRIDGE e PARKINSON, 2012; BÄCHTIGER e PARKINSON, 2019; DEAN et. al., 2019). Em contraste com as abordagens mais antigas de sistemas (por exemplo, EASTON 1965), precisamos ser bastante propositivos, construindo questôes focadas em sistemas de base normativa, e que orientam tanto a construçáo da teoria quanto a empiria. Precisamos de uma abordagem de sistemas focada nas principais funçóes normativas da democracia para identificar e medir os deficits democráticos das instituiçôes da democracia representativa, o que por sua vez ajudará a identificar quais tipos de inovações democráticas podem ter como alvo esses deficits (WARREN, 2017).

Em segundo lugar, para rastrear as forças que estão afetando a vida das pessoas, precisamos ir além da concepção estatista de grande parte da teoria e da prática democrática contemporânea. Precisamos ser capazes de pensar sobre "democracia" como algo genérico, como autogoverno coletivo que está intimamente relacionado com as coisas que estruturam as capacidades das pessoas, independente de serem ou não controláveis por políticas organizadas jurisdicionalmente. Um dos conceitos mais promissores para esse repensar é o do "princípio de todos os afetados" - a ideia de que os afetados por algum assunto coletivo devem ter uma palavra a dizer sobre o tema que lhes afetam. Embora essa possibilidade teórica ainda esteja subdesenvolvida, ela representa uma forma possível de reconstruir a teoria democrática, de modo que ela permaneça relevante em um mundo interconectado, e aberta a inovaçóes democráticas acima, abaixo e além do estado (FUNG, 2013).

Em terceiro lugar, a demanda por inovações democráticas nos contextos de déficit democrático dependerá, em parte, dos tipos específicos de sistemas constitucionais e eleitorais que estão em déficit. O campo emergente das inovaçôes 
democráticas precisa desenvolver parcerias estreitas com o trabalho comparativo "dominante" sobre as instituições democráticas. Até o momento, essas parcerias não têm sido fáceis (ver CAIN, DALTON e SCARROW, 2003), não por causa de diferenças políticas ou ideológicas, mas simplesmente porque as inovaçôes democráticas (como o termo sugere) são, em sua maioria, novas. À medida que o campo da ciência política se tornou mais rigoroso na pesquisa empírica, particularmente na pesquisa quantitativa, ele se tornou mais conservador, no sentido de que os pesquisadores tendem a procurar problemas onde potencialmente têm os dados para respondê-los. Um resultado é que a ciência política continua fortemente voltada para o estudo do voto, das eleiçôes e da opinião pública, produzindo um compromisso ideológico tácito com as instituiçóes legadas da democracia eleitoral, e excluindo as inovaçôes democráticas. Em contraste, o campo das inovaçôes democráticas atualmente carece de dados, especialmente o tipo de dados que dão suporte à pesquisa quantitativa. Essa circunstância deverá mudar, mas é improvável que a ciência política dominante impulsione a mudança devido ao seu investimento em dados disponíveis. O campo das inovações democráticas precisa construir os dados que possam apoiar a integração da pesquisa comparativa com a ciência política (ver PARTICIPEDIA, 2020).

Em quarto lugar, até agora, o campo das inovaçóes democráticas tem sido mais robusto nos processos que buscam respostas a problemas mais localizados - como transporte, saúde e planejamento urbano. Não nos concentramos nos déficits democráticos que resultam das dinâmicas estruturais de larga escala: especialmente os mercados globais, a desigualdade estrutural e a estagnação salarial, a política fiscal, questôes de guerra e segurança, e de imigração, problemas que estão impulsionando o ressurgimento do populismo, incluindo suas variantes autoritárias. $\mathrm{O}$ mais impressionante é que nos dedicamos muito pouco para pensar em como as inovaçôes democráticas podem interagir com os elementos da estrutura social baseados no mercado, e que não são controlados diretamente por governos ou associaçóes da sociedade civil. De forma um tanto alarmante, as capacidades do Estado em regular os mercados na promoçáo de bens sociais mais amplos, e de controlar as suas externalidades, parecem estar desaparecendo. Nem pensamos muito em como as inovaçôes democráticas podem se integrar às políticas externas, particularmente aquelas que são progressivamente globais. Essas são as áreas atualmente mais urgentes, das quais as democracias representativas mais carecem de capital político. Precisamos nos concentrar em inovaçóes democráticas que possam reabastecer as reservas perigosamente baixas de capital político nas instituiçóes da democracia representativa, reconhecendo, é claro, que o Reino Unido, os EUA e a Itália estão com mais problemas 
do que os países escandinavos. Pelas mesmas razôes, precisamos conectar as inovaçôes democráticas com a governança transnacional, de modo a atenuar as ondas atuais de nacionalismo reativo e destrutivo, a exemplo do Brexit.

Em quinto lugar, na medida em que a maioria das inovaçôes democráticas são (corretamente) focadas em envolver as pessoas de forma mais ampla e profunda na governança, precisamos pensar sobre as divisóes políticas do processo para que seu (em última análise, limitado) tempo, energia e inteligência sejam usados com o máximo efeito (MACKENZIE e WARREN, 2012; WARREN e GASTIL, 2015). Como e onde uma maior participação do cidadão pode somar e democratizar os sistemas políticos? Quando precisamos de profissionais, tanto na política quanto nas agências? Onde as inovaçóes democráticas podem agregar maior capacidade e legitimidade? Aqui, precisamos pensar sobre a escassez de tempo, atenção e conhecimento, tanto no que diz respeito às demandas sobre os cidadãos, quanto às demandas sobre governos, legislaturas, comissóes e agências. Precisamos pensar sobre a economia dos investimentos dos cidadãos: as divisóes de trabalho democráticas devem maximizar os seus impactos, ao mesmo tempo que minimizar os seus encargos. Em parte, esse problema exige que pensemos sobre as relaçóes de confiança: quando fará sentido para os cidadáos confiarem em outros para representá-los e quando eles devem gastar seus escassos recursos participativos (WARREN e GASTIL, 2015)?

Em sexto lugar, precisamos identificar e compreender os incentivos para as inovaçóes democráticas nos sistemas existentes. Por que as elites os adotariam (BEAUVAIS, WARREN e YAYLACI, 2019)? Como parte desse problema geral, torna-se cada vez mais essencial, para o campo, encontrar maneiras de educar as elites eleitas para que compreendam a gama de inovaçôes democráticas, evitando que usem processos inadequados (ou que não entendem) quando se deparam com problemas políticos - mais uma vez, o Brexit sendo o exemplo mais dramático e prejudicial enquanto complementação da democracia representativa com um processo "direto". Havia e há alternativas com credenciais democráticas muito mais fortes - se apenas as elites eleitas do Partido Conservador tivessem o conhecimento e as motivaçôes para recorrer a elas.

Finalmente, precisamos encontrar maneiras de avaliar normativamente as consequências das inovaçôes democráticas no nível do sistema (cf. BÄCHTIGER e PARKINSON, 2019, WARREN, 2017). Por exemplo, adicionar mais locais de participação para o cidadão não significa, simplesmente, ampliar a voz daqueles que já têm recursos políticos? Ou podemos projetar inovaçôes democráticas que gerem mais 
inclusão para aqueles que têm sido excluídos? Em que medida elas produzem decisóes mais bem informadas e mais deliberativas? Podem fornecer ganhos de legitimidade que aumentem as capacidades de tomada de decisão, incluindo maior confiança no governo? Ou gerar maior compromisso do cidadão para melhorar a distribuição de bens públicos, as proteçóes, e o bem-estar social? Isso é, podemos estimar as contribuiçôes normativas das inovaçôes democráticas funcionando enquanto parte de uma ecologia política mais ampla?

Esses são os tipos de questôes necessárias para aprofundarmos os estudos e teorias, se apostarmos na democracia como uma maneira de enfrentar os desafios atuais do projeto democrático.

\section{Conclusão}

As democracias desenvolvidas não estão em crise, mas enfrentando déficits democráticos que estão corroendo a sua capacidade de assegurar boas sociedades. $\mathrm{O}$ legado acumulado pelas instituiçóes da democracia representativa está mostrando isso. Elas surgiram de projetos voltados para democratizar o Estado-nação quando eram as formas de organização mais poderosas, em um mundo menos complexo, e em que os destinos dos povos eram menos interconectados. Agora precisamos inovar com urgência para expandir as capacidades das democracias representativas, fortalecendo e democratizando as organizações políticas para além das fronteiras nacionais. Precisamos inovar para combinar a evolução das expectativas democráticas dos cidadãos com o desenvolvimento institucional. Estamos em um bom começo - o campo das inovaçôes democráticas está crescendo e se consolidando. O campo agora deve crescer de forma suficientemente rápida e inteligente para suprir os deficits das instituiçôes da democracia representativa.

- Mark E. Warren é Professor Titular da Cátedra Merilees para o Estudo da Democracia no Departamento de Ciência Política da Universidade de British Columbia. E-mail: mark.warren@ubc.ca. 


\section{Referências}

ACKERMAN, Bruce; FISHKIN, James S. Deliberation Day. New Haven: Yale University Press, 2004. ALEXANDER, Amy C; WELZEL, Christian. The Myth of Deconsolidation: Rising Liberalism and the Populist Reaction. Hamburg: ILE Working Paper Series, 2017.

BÄCHTIGER, Andre; DRYZEK, John; MANSBRIDGE, Jane; WARREN, Mark E., (eds.) The Oxford Handbook of Deliberative Democracy. Edited with Oxford University Press, 2018.

BÄCHTIGER, Andre; PARKINSON, John. Mapping and Measuring Deliberation: Toward a New Deliberative Quality. Oxford: Oxford University Press, 2019.

BARBER, Benjamin. Strong Democracy: Participatory Politics for a New Age. Berkeley: University of California Press, 2003.

BEAUVAIS, Edana; WARREN, Mark E. What Can Deliberative Mini-Publics Contribute to Democratic Systems?. European Journal of Political Research, v. 58, n. 3, p. 893-914, 2019.

BEAUVAIS, Edana; WARREN, Mark E.; YAYLACI, Sule. When, Where, and Why Might Elected Political Elites Adopt Democratic Innovations?. European Consortium for Political Research General Conference, Wroclaw, Poland, September 4-7, 2019.

BELL, Daniel. The China Model: Political Meritocracy and the Limits of Democracy. Princeton: Princeton University Press, 2015.

BRENNAN, Jason. Against Democracy. Princeton: Princeton University Press, 2017.

CAIN, Bruce; DALTON, Russell; SCARROW, Susan. Democracy Transformed: Expanding Political Opportunities in Advanced Industrial Democracies. Oxford: Oxford University Press, 2003.

CITRIN, Jack. Proposition 13 and the Transformation of California Government. California Journal of Politics and Policy, v. 1, n. 1, p. 1-9, 2009.

CROZIER, Michael; HUNTINGTON, Samuel; WATANUKI, Joji. The Crisis of Democracy. New York: New York University Press, 1975.

DALTON, Russell. J. Citizen Politics. Public Opinion and Political Parties in Advanced Industrial Democracies. Washington DC: Congressional Quarterly Press, 2013.

DEAN, Rikki; RINNE, Jonathan; GEISSEL, Brigitte. Systematizing Democratic Systems Approaches: Seven Conceptual Building Blocks. Democratic Theory, v. 6, n. 2, p. 41-57, 2019.

DIAMOND, Larry. Breaking Out of the Democratic Slump. Journal of Democracyv. 31, n. 1, p. 3650, 2020.

DRYZEK, John S. Deliberative Global Politics: Discourse and Democracy in a Divided World. Cambridge: Polity Press, 2006.

DRYZEK, John S. The Politics of the Earth: Environmental Discourses. Oxford University Press, 2013. DRYZEK, John; NIEMEYER, Simon. Discursive Representation. American Political Science Review, v. 102, n. 4, p. 481-493, 2008.

EASTON, David. A Framework for Political Analysis. Englewood Cliffs: Prentice Hall, 1965.

EDELMAN. Edelman Trust Barometer 2019. Disponível em: http://www.edelman.com. Acesso em: 25 jul. 2019.

EL-WAKIL, Alice. The Deliberative Potential of Facultative Referendums: Procedure and Substance in Direct Democracy. Democratic Theory, v. 4, n. 1, p. 59-78, 2017.

ELSTUB, Stephen; ESCOBAR, Oliver. The Handbook of Democratic Innovation and Governance. Cheltenham: Edward Elgar Publishing, 2019. 
FARRELL, David M.; SUITER, Jane. Reimagining Democracy: Lessons in Deliberative Democracy from the Irish Front Line. Ithaca: Cornell University Press, 2019.

FERRIN, Monica; KREISI, Hanspeter. How Europeans View and Evaluate Democracy. Oxford: Oxford University Press, 2014.

FISHKIN, James S. Democracy When the People are Thinking. Oxford: Oxford University Press, 2018. FUNG, Archon. Deliberative Democracy and International Labor Standards. Governance, v. 16, n. 1, p. 51-71, 2003a.

FUNG, Archon. Recipes for Public Spheres: Eight Institutional Design Choices and Their Consequences. Journal of Political Philosophy, n. 11, p. 338-367, $2003 \mathrm{~b}$.

FUNG, Archon. Varieties of Participation in Complex Governance. Public Administration Review, v. 66, p. 66-75, 2006.

FUNG, Archon. The Principle of Affected Interests: An Interpretation and Defense. Representation: Elections and beyond, edited by J. Nagel and R. Smith. Philadelphia: University of Pennsylvania Press, p. 236-268, 2013.

GALSTON, William A. The Populist Challenge to Liberal-Democracy. Journal of Democracy, v. 29, n. 2, p. 5-19, 2018.

GASTIL, John; WRIGHT, Erik Olin. Legislatures by Lot: Transformative Designs for Deliberative Governance. London: Verso, 2019.

GASTIL, John; KNOBLOCH, Katherine. Hope for Democracy. How Citizens Can Bring Reason Back into Politics. Oxford: Oxford University Press, 2020.

GASTIL, John. Communication and Public Deliberation. Thousand Oaks: Sage Publishers, 2008.

GILENS, Martin. Affluence and Influence: Economic Inequality and Political Power in America. Princeton: Princeton University Press, 2012.

GOODIN, Robert E.; DRYZEK, John S. Deliberative Impacts: the Macro-Political Uptake of MiniPublics. Politics \& society, v. 34, n. 2, p. 219-244, 2006.

GRANT, Ruth W.; KEOHANE, Robert O. Accountability and Abuses of Power in World Politics. American Political Science Review, v. 99, n. 1, p. 29-43, 2005.

HEINELT, Hubert. Handbook on Participatory Governance. Cheltenham: Edward Elgar Publishing, 2018.

HUBER, Evelyne; GUNDERSON, Jacob; STEPHENS, John D. Private Education and Inequality in the Knowledge Economy. Policy and Society, v. 39, n. 2, p. 171-188, 2020.

ISERNIA, Pierangelo; FISHKIN, James S. The EuroPolis Deliberative Poll. European Union Politics, v. 15, n. 3, p. 311-327, 2014.

JACQUET, Vincent; VAN DER DOES, Ramon. The Consequences of Deliberative Minipublics: Systematic Overview, Conceptual Gaps, and New Directions. Representation, p. 1-11, 2020.

KALDOR, Mary. The Idea of Global Civil Society. International Affairs, v. 79, n. 3, p. 583-593, 2003. KEANE, John. Global Civil Society? Cambridge: Cambridge University Press, 2003.

KEOHANE, Robert O.; MACEDO, Stephen; MORAVCSIK, Andrew. Democracy-Enhancing Multilateralism. International Organization, v. 63, p. 1-31, 2009.

KRIESI, Hanspeter. 2020. Is There a Crisis of Democracy in Europe? Politische Vierteljahresschrift, v. 61, p. 237-260, 2020.

LANDWEHR, Claudia. FAAS, Thorsten. Who Wants Democratic Innovations, and Why. Mainz: Universität Mainz, 2016. 
LANG, Amy; WARREN, Mark E. Supplementary Democracy? Democratic Deficits and Citizens' Assemblies. In: LENARD, Patti; SIMEON, Richard (org.). Imperfect Democracies. New York, University of British Columbia Press, 2012, p. 291-314.

LATINNO PROJECT. The Latinno Project. Disponível em: https://latinno.net. Acesso em: 26 Jul. 2019.

LEE, Caroline W. Do-It-Yourself Democracy: The Rise of the Public Engagement Industry. Oxford: Oxford University Press, 2014.

LEIB, Ethan. Deliberative Democracy in America: A Proposal for a Popular Branch of Government. University Park: Pennsylvania State Press, 2010.

LEIGHNINGER, Matthew. The Next Form of Democracy: How Expert Rule is Giving Way to Shared Governance-And Why Politics Will Never Be the Same. Nashville: Vanderbilt University Press, 2006.

LEVITSKY, Steven; ZIBLATT, Daniel. How Democracies Die. New York: Broadway Books, 2018.

MACKENZIE, Michael K.; WARREN, Mark E. Two Trust-Based Uses of Minipublics in Democratic Systems. In: MANSBRIDGE, Jane; PARKINSON, John (org.). Deliberative Systems. Cambridge: Cambridge University Press, 2012, p. 95-124.

MANSBRIDGE, Jane; PARKINSON, John (org.). Deliberative Systems. Cambridge: Cambridge University Press, 2012.

MCKAY, Spencer. A Democratic Theory of Ballot Measures. 2019. 201f. Tese (PhD) - The Faculty of Graduate and Postdoctoral Studies, The University of British Columbia. Vancouver, 2019.

MONTANARO, Laura. Who Elected Oxfam?: A Democratic Defense of Self-Appointed Representatives. Cambridge: Cambridge University Press, 2017.

MORAVCSIK, Andrew. Affirming Democracy in International Organizations. Global Challenges in 2030, v. 1, n. 4, p. 13-14, 2010.

MOUNK, Yascha. The People vs. Democracy: Why Our Freedom is in Danger and How to Save It. Cambridge: Harvard University Press, 2018.

NEBLO, Michael A.; ESTERLLING, Kevin M.; KENNEDY, Ryan P.; SOKHEY, Anand E. Who Wants to Deliberate and Why? American Political Science Review, v. 104, n. 3, p. 566-583, 2010.

NEWTON, Kenneth. GEISSEL, Brigette. Evaluating Democratic Innovations: Curing the Democratic Malaise? London: Routledge, 2012.

NORRIS, Pippa. INGLEHART, Ronald. Cultural Backlash: Trump, Brexit, and the Rise of Authoritarian Populism. Cambridge: Cambridge University Press, 2018.

NORRIS, Pippa. Democratic Deficit. Critical Citizens Revisited. Cambridge: Cambridge University Press, 2011.

NORRIS, Pippa. Is Western Democracy Backsliding? Diagnosing the Risks. Cambridge, MA: HKS Faculty Research Working Paper Series, 2017.

OECD. Innovative Citizen Participation and New Democratic Institutions: Catching the Deliberative Wave. Paris: OECD Publishing, 2020.

ORTMANN, Stephan; THOMPSON, Mark R. China and the Singapore Model. Journal of Democracy, v. 27, n. 1, p. 39-48, 2016.

PARTICIPEDIA. 2020. The Participedia Project. Disponível em: https://participedia.net. Acesso em: 11 Jul. 2020. 
ROSANVALlON, Pierre. Democratic Legitimacy: Impartiality, Reflexivity, Proximity. Princeton: Princeton University Press, 2011.

SCARROW, Susan E. Political Parties and Democracy in Theoretical and Practical Perspectives: Implementing Intraparty Democracy. Washington: National Democratic Institute for International Affairs, 2005.

SINTOMER, Yves; HERZBERG, Carston; RÖCKE, Anja; ALLEGRETTI, Giovanni. Transnational Models of Citizen Participation: The Case of Participatory Budgeting. Journal of Public Deliberation, v. 8, n. 2, p. 70-116, 2012.

SMITH, Graham. Democratic Innovations. Cambridge: Cambridge University Press, 2009.

SØRENSEN, Eva. Democratic Theory and Network Governance. Administrative Theory and Praxis, v. 24, n. 4, p. 693-720, 2002.

TEORELL, Jan. A Deliberative Defence of Intraparty Democracy. Party Politics, v. 5, n. 3, p. 363-382, 1999.

TREISMAN, Daniel. Is Democracy in Danger? A Quick Look at the Data. Conference on Democratic Backsliding and Electoral Authoritarianism. New Haven: Yale University, 7 Jun. 2018.

WAMPLER, Brian. Participatory Budgeting in Brazil: Contestation, Cooperation, and Accountability. University Park: Pennsylvania State Press, 2010.

WARREN, Mark E. What Can Democratic Participation Mean Today? Political Theory, v. 30, p. 678702, 2002.

WARREN, Mark E. A Second Transformation of Democracy? In: CAIN, Bruce; DALTON, Russell; SCARROW, Susan (org.). Democracy Transformed: Expanding Political Opportunities in Advanced Industrial Democracies. Oxford: Oxford University Press, p. 223-249, 2003.

WARREN, Mark E. Citizen Representatives. In: WARREN, Mark; PEARSE, Hilary (org.). Designing Deliberative Democracy: The British Columbia Citizens' Assembly. Cambridge: Cambridge University Press, p. 50-69, 2008.

WARREN, Mark. E. Governance-Driven Democratization. Critical Policy Studies, v. 3, n. 1, p. 3-13, 2009.

WARREN, Mark E. A Problem-Based Approach to Democratic Theory. American Political Science Review, v. 111, n. 1, p. 39-53, 2017.

WARREN, Mark E. GASTIL, John. Can Deliberative Minipublics Address the Cognitive Challenges of Democratic Citizenship? Journal of Politics, v. 77, n. 2, p. 562-74, 2015.

Texto recebido em 18 de março de 2021. Aprovado em 30 de março de 2021. 